\title{
Vagus Nerve
}

National Cancer Institute

\section{Source}

National Cancer Institute. Vagus Nerve. NCI Thesaurus. Code C12812.

The tenth cranial nerve. It is the longest cranial nerve. It originates in the medulla and exits the cranium through the jugular foramen. It supplies various muscles, including muscles of the pharynx and soft palate. 